\title{
4OR: Year 4
}

\section{Editorial notes}

\author{
Denis Bouyssou $^{1 \star}$, Silvano Martello ${ }^{2 \star \star}$, Frank Plastria $^{3 \star \star \star}$ \\ 1 CNRS \\ 2 Università di Bologna \\ 3 Vrije Universiteit Brussel \\ Received: January 2006
}

Three years ago, we were writing in the editorial notes inserted in the first issue of this journal (see Bouyssou et al., 2003) that "Starting a new journal is a challenge". It was. But three years after its launching, $4 O R$ is still there... and appears to be in reasonably good condition. Indeed:

- we have been in position to consistently follow our publishing pace of 4 issues of approximately 85 pages a year;

- the journal now has an electronic edition available at http://link. springer.de/link/service/journals/10288/index.htm and is part of the new electronic package deal offered by Springer to libraries. This will undoubtedly increase the number of readers of the papers that we publish;

- the growing international impact of the journal was reflected by a change in its name. Whereas it was " $4 O R$, Quarterly Journal of the Belgian, French and Italian Operations Research Societies", starting with Issue 2 of Volume 3, it is now " $4 O R$, A Quarterly Journal of Operations Research", a change that was approved by Springer and the three promoting societies.

Our term of three years as editors ended in December 2005. We thought this was an appropriate time to give our readers information on the first

* LAMSADE, Université Paris Dauphine, Place du Maréchal de Lattre de Tassigny, F-75775 Paris Cedex 16, France, tel: +33 1440548 98, fax: +3314405 40 91, e-mail: 4or@lamsade.dauphine.fr.

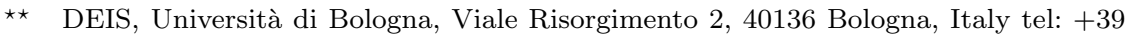
051 2093022, fax: +39051 2093073, e-mail: 4or@deis.unibo.it.

$\star \star \star$ MOSI, Department of Mathematics, Operational Research, Statistics and Information Systems for Management, Vrije Universiteit Brussel, Pleinlaan 2, B-1050 Brussels, Belgium, tel: +32 2 6293609, fax: +32 2 6293690, e-mail: 4or.be@vub.ac.be. 
three years in the life of the journal. Furthermore, since our term has been renewed for the next three years, it is also time to think of plans for the future. This is the purpose of these notes.

\section{What has been published?}

As announced in our earlier editorial notes, the journal was intended to publish papers of five different kinds:

- invited surveys;

- regular papers;

- abstracts of PhD Theses;

- industrial papers;

- display papers.

All types of papers, except "display papers", were indeed published in our first three years of existence. Furthermore, experience has induced us to allow for an additional type of paper, educational papers, aiming at giving an up-to-date exposition of classical OR problems that are frequently used in OR classes, or throwing a novel light on such. In addition, we occasionally publish book reviews as regular (short) papers in which an invited scientist expresses his/her opinion on a recent relevant book in our field. Three of them were published so far.

A synthetic view of what was published in the first three volumes appears in Table 1.

\begin{tabular}{cc}
\hline type of & $\begin{array}{c}\text { number of } \\
\text { papers }\end{array}$ \\
\hline papers & 11 \\
Invited surveys & 1 \\
Regutional papers & 37 \\
Industrial papers & 4 \\
PhD Thesis abstracts & 17 \\
\hline
\end{tabular}

Table 1. Types of papers published (2003-2005)

Note: 3 of the 37 regular papers are book reviews

\subsection{Regular papers}

Regular papers are the core of the journal. Excluding book reviews, we published 34 such papers giving an average number of 2.8 regular papers per issue. Information on submissions and on the selection process is given in Section 2. Table 2 details the country of origin of the papers published (for 
papers with multiple authors, we conventionally record the nationality of the majority of authors, using the country of origin of the first author to break ties). The good news here is that Belgium, France and Italy account for $47 \%$ of all papers, showing that the research output of these three countries is well represented in $4 O R$ but also that the journal is attracting authors from outside the three promoting countries.

\begin{tabular}{ccc}
\hline country & $\begin{array}{c}\text { number of } \\
\text { papers }\end{array}$ & percentage \\
\hline Italy & 8 & $23.7 \%$ \\
France & 5 & $14.8 \%$ \\
Belgium & 3 & $8.8 \%$ \\
UK & 3 & $8.8 \%$ \\
Germany & 3 & $8.8 \%$ \\
Portugal & 2 & $5.9 \%$ \\
Switzerland & 2 & $5.9 \%$ \\
USA & 2 & $5.9 \%$ \\
Algeria & 1 & $2.9 \%$ \\
Luxembourg & 1 & $2.9 \%$ \\
Morocco & 1 & $2.9 \%$ \\
South Africa & 1 & $2.9 \%$ \\
Turkey & 1 & $2.9 \%$ \\
Ukraine & 1 & $2.9 \%$ \\
\hline Total & 34 & $100 \%$ \\
\hline
\end{tabular}

Table 2. Origin of regular papers published (excluding book reviews) (2003-2005)

Our initial intention was to publish only short papers in this section of the journal and the fuzzy constraint of 12 pages was announced. We quickly came to realize that this constraint, although soft, was detracting many authors to submit to this journal as soon as their text was significantly exceeding the limit. Hence, we have removed this constraint; short papers are nevertheless favored and are more likely to be processed within a short period of time.

The average length of the regular papers published (excluding book reviews) is 13.3 pages with a minimum of 4 pages and a maximum of 22 pages.

\begin{tabular}{ccc}
\hline length & $\begin{array}{c}\text { number of } \\
\text { papers }\end{array}$ & percentage \\
\hline$x \leq 10$ & 9 & $26.5 \%$ \\
$11 \leq x \leq 14$ & 7 & $20.6 \%$ \\
$15 \leq x \leq 18$ & 16 & $47.1 \%$ \\
$19 \leq x$ & 2 & $5.8 \%$ \\
\hline Total & 34 & $100 \%$ \\
\hline
\end{tabular}

Table 3. Length in pages of regular papers (excluding book reviews) published (20032005) 


\begin{tabular}{c}
\hline Bilevel programming \\
Classification and OR \\
Combinatorial auctions \\
Complexity of nonlinear programming \\
Counting and enumeration complexity \\
Dial-a-Ride problem \\
Ethics in OR/MS \\
Frequency assignment problem \\
Lagrangian relaxation \\
Lifting of valid inequalities \\
Production planning \\
\hline
\end{tabular}

Table 4. Topics covered in invited surveys (2003-2005)

\begin{tabular}{cc}
\hline country & $\begin{array}{c}\text { number of } \\
\text { surveys }\end{array}$ \\
\hline Canada & 3 \\
France & 3 \\
Belgium & 2 \\
Germany & 1 \\
Italy & 1 \\
USA & 1 \\
\hline
\end{tabular}

Table 5. Origin of invited surveys (2003-2005)

This is detailed in Table 3. Around half the papers published are under 14 pages, which, we think, is in line with our initial announcement.

Although 34 papers is too small a number to produce meaningful statistics, we have the feeling that the papers that were published are representative of the main areas of research in OR.

\subsection{Invited surveys}

During the period 2003-2005, we have published 11 invited surveys, one per issue (except for one issue in which the invited survey was replaced by an educational paper). The average length of these papers was 31.6 pages (minimum 13, maximum 57). Hence, a substantial part of the journal is devoted to these texts. Whereas the room taken by these surveys decreases the space left for regular papers, our belief is that these papers will tend to be frequently referenced, therefore increasing the visibility of the journal, which should be beneficial for all authors in the long run.

Papers in this section are solicited by one of us and are reviewed collectively by the three of us. We have tried hard to solicit papers dealing with important or emerging fields of OR (see Table 4). Furthermore, we have strived to obtain papers from authors coming from a large variety of countries (see Table 5; we use the same convention as above). 


\subsection{PhD Thesis abstracts}

The journal publishes abstracts of $\mathrm{PhD}$ Theses defended in Belgium, France and Italy (or by Belgian, French and Italian students studying abroad). These abstracts are published under the responsibility of the supervisor of the work. We have received a total of 17 abstracts. We published all of them although we retain the right not to do so in the future. Among these abstracts, 7 were coming from Belgium and 5 from both Italy and France. Most important universities in these three countries granting $\mathrm{PhD}$ Theses in OR are represented.

Denis Bouyssou (4or@lamsade.dauphine.fr) is responsible for this section: he reviews the abstracts, making sure that they are informative and that their presentation remains homogeneous. Authors willing to submit the abstract of their $\mathrm{PhD}$ Thesis should browse through previous issues of the journal to get a feeling of the standard presentation that has been adopted.

Abstracts should be 3 or 4 pages long. It is advisable that authors use space optimally and do not start a page that would not be reasonably full.

\subsection{Industrial section}

Industrial papers consist of case studies, state-of-the-art papers on the applications of OR techniques or reflections on the practice of OR. We have published 4 papers in this section (using the same conventions as above, 1 from Canada, 1 from Italy, 1 from Switzerland and 1 from the UK). This relatively small number is somewhat disappointing to us. Although we are well aware of the fact that practitioners do not have much time or interest to write a paper, we shall work hard to increase the number of submissions to this section.

\subsection{Display section}

This section was intended for research groups and OR firms within the community of the three countries, giving them the opportunity to describe their recent directions of research and development and put their achievements in perspective.

The three promoting societies were responsible for the creation of this section of the journal. Unfortunately, we did not receive any submission in this section during the period 2003-2005. We interpret this lack of submission as the sign that research groups have little interest to present their activity in such a way: they already produce many reports on their research activities for evaluation purposes that are, in general, widely made available on the Internet. Our feeling is therefore that this section does not answer a real need of our research community and we have decided to close it. 


\section{How were the papers selected?}

This section gives information on the reviewing process of regular papers for which a decision was taken before 31 December 2005.

Except for a case of plagiarism that was fortunately detected (see Bouyssou et al., 2006, for details on this astonishing case) the reviewing process of the papers was rather smooth, although our policy towards major revisions has been considered tough by some authors. The collaboration between the three editors proved effective and efficient. Our purely electronic way of handling papers revealed swift and economical.

\subsection{Rejection rate}

Submissions have been following a regular pace. It is too early to produce any significant statistics on them. On 31 December 2005, a total of 189 regular papers (excluding book reviews) were fully processed. A total of 55 papers were accepted, meaning an overall rejection rate of $71 \%$. This rejection rate is rather high. We are indeed happy to say that, in spite of the uncertainty involved in the launching of a new journal, we have never been led to publish a paper without being fully convinced of its quality. When interpreting this rejection rate, two facts should be kept in mind:

- the launching of a new journal inevitably attracts "bottom of drawers" papers, likely to have been rejected elsewhere. Such poor quality papers were consistently rejected, therefore increasing the rejection rate;

- the editorial policy of the journal, in order to ensure a fast and fair processing of the manuscripts, is to reject all papers needing a major revision. After they have been revised, such papers may however be resubmitted to the journal, in which case they are considered as new submissions.

This makes the comparison of our rejection rate with the one in other journals (when they publish it ...) somewhat tricky.

\subsection{Time before decision}

The mean time between the reception of the paper and the communication of the decision to the authors was 142 days (4.7 months) with a minimum of 0 days and a maximum of 807 days. Information on the reviewing time of regular papers is summarized in Table 6 and Figure 1. For the 134 papers that were rejected, the mean time before decision was 125 days (4.1 months) with a minimum time of 0 days (paper rejected the day it was received) and a maximum time of 807 days (this case being rather exceptional: the average time before rejection is 119 days without this outlier). 


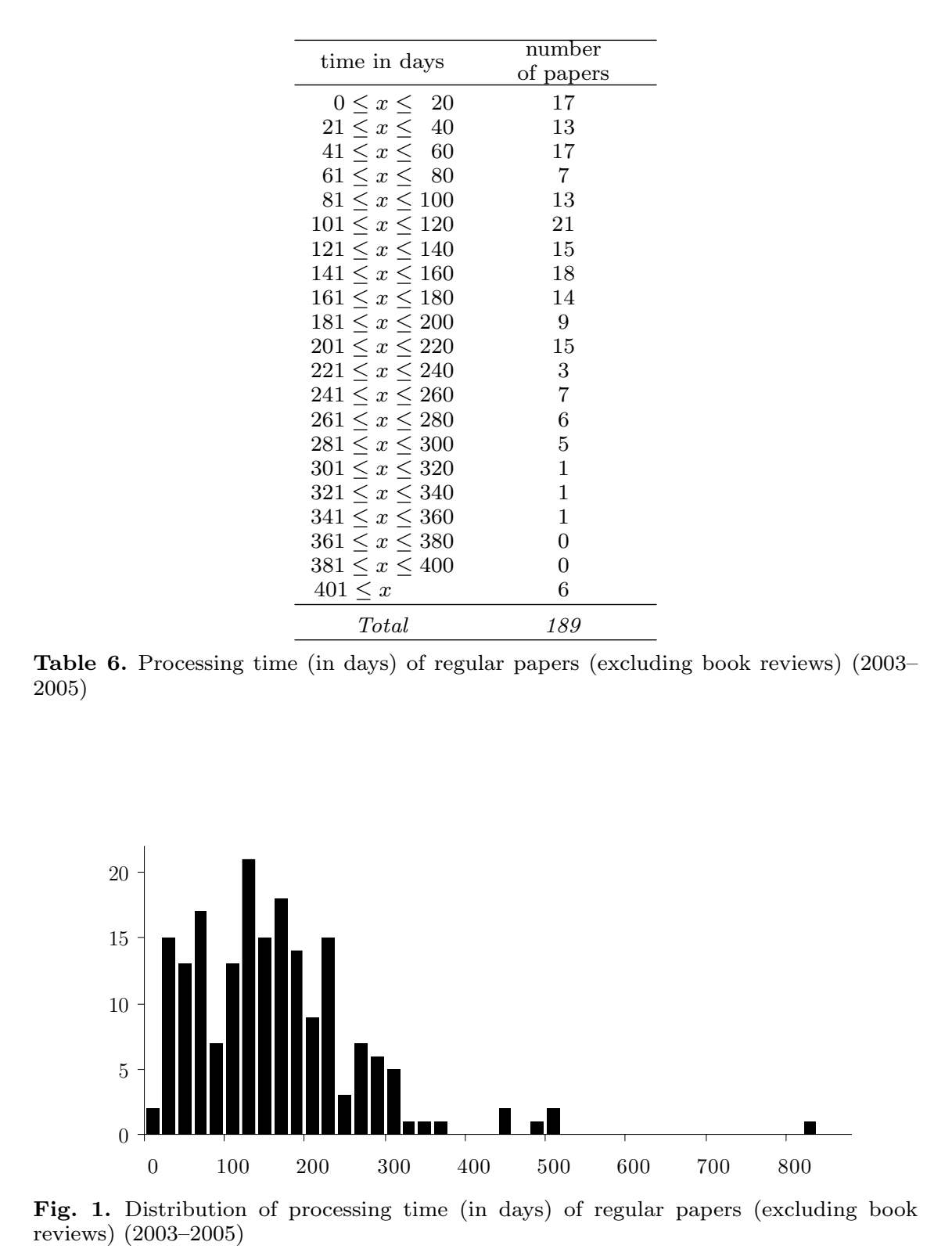


For the 55 papers that were accepted the average time before decision was 183 days ( 6.1 month) with a minimum of 35 days and a maximum of 472 days.

It is too early to produce statistics on the time between acceptance and publication. This is all the more true since the launching period of the journal produced many outliers. At the end of December 2005, 34 regular papers (excluding book reviews) were published among the 55 that were accepted. This means that 21 papers are now in the publishing queue.

\subsection{Origin of papers}

Table 7 summarizes the country of origin of the 189 regular papers that were processed (when there are multiple authors, the convention is, here, to record the country in which the first author is working). The fact that the journal is attracting papers from outside the three promoting countries is happily confirmed. It should also be noticed that there is no significant difference between the rejection rate according to the country of origin of the authors: papers coming from Belgium, France or Italy obviously do not receive a special treatment. A notable exception are papers coming from countries in which academic institutions are still poorly structured and/or financed. We are sorry to say that, although we received many papers from such countries and in spite of our willingness to help colleagues doing good work under poor conditions, we have only been able to accept very few of these papers.

\begin{tabular}{lccc}
\hline country & $\begin{array}{c}\text { number of papers } \\
\text { received }\end{array}$ & $\begin{array}{c}\text { number of papers } \\
\text { accepted }\end{array}$ & rejection rate \\
\hline Europe & 114 & 48 & $58 \%$ \\
$\quad$ among which BIF & 80 & 31 & $61 \%$ \\
UJTSASA & 16 & 4 & $75 \%$ \\
Rest of world & 59 & 3 & $94 \%$ \\
\hline Total & 189 & 55 & $71 \%$ \\
\hline
\end{tabular}

Table 7. Origin of regular papers (excluding book reviews) (2003-2005)

BIF: Belgium, Italy, France

UJTSASA: USA, Japan, Taiwan, South America, South Africa

\section{What are our plans?}

Being only three years old, $4 O R$ is still in its infancy... and therefore still vulnerable to the most common infantile diseases of journals. Since our 
present policy has been reasonably successful, we do not plan any revolutionary change for the next three years. Clearly, we will continue to work hard to attract good papers and to select them in the most careful way.

The journal is currently indexed and/or abstracted in Abstracts in Operations Research, Zentralblatt für Mathematik and Mathematical Reviews. One major issue on our agenda is to increase the visibility of the journal. A medium term objective is indeed to have the journal included in the major bibliometrics databases. This, in particular, means that papers that we published have to be cited. Our new electronic edition will undoubtedly help in this respect... but we also need help from our readers. A journal cannot live without the active involvement of the scientific community behind it. Indeed, we expect our readers:

- to promote the journal,

- to submit good papers (and to suggest others to submit good papers),

- to cite papers published in the journal,

- to accept refereeing tasks and to give motivated and constructive advice without undue delay,

- to make the editors aware of new emerging fields that would give nice invited surveys,

- to give incentives to their doctoral students to submit an abstract of their $\mathrm{PhD}$ Thesis to the journal.

Furthermore, we are eager to receive comments and suggestions on the present state of the journal and possible directions of improvement. We will continue to do our best to make this journal a useful tool for any member of the three promoting OR societies and, more generally, for the whole OR community.

These notes are also the occasion to warmly thank our board of Area Editors and all the persons that have accepted to referee papers for the journal (the list of referees is published every year at the end of the fourth issue of each volume). Their help has been instrumental in the success of the journal.

\section{References}

Bouyssou, D., Martello, S., and Plastria, F. (2003). $4 O R$ for what purpose? $4 O R, 1(1)$ :1-

Bouyssou, D., Martello, S., and Plastria, F. (2006). A case of plagiarism: Dănuţ Marcu. $4 O R, 4(1): 9-11$ 